\title{
Sperm retention cysts in the efferent duct and testicular atrophy of TE inbred rats
}

\author{
H. Ikadai*, H. Fujita, C. Ajisawa and T. Imamichi \\ The Imamichi Institute for Animal Reproduction, 3-100 Nissin-cho, Omiya-shi, 330 Japan
}

\begin{abstract}
Summary. Sperm retention cysts were observed in the efferent duct of TE inbred rats at 15 weeks of age. Spermatozoa agglutinated in the efferent duct with destruction of the epithelium. Testicular weight increased or decreased. Diameter of the seminiferous tubules was enlarged in testes that increased in weight and germinal cells degenerated in the atrophied testes. After 30 weeks of age, the tubules of the efferent duct were sometimes replaced by scars and testicular atrophy became more frequent. In 3 out of 5 normal rats united by parabiosis with TE males for 25-27 days, cysts occurred in the efferent duct.
\end{abstract}

\section{Introduction}

Sperm retention cysts or spermatogranulomata in the efferent ducts are not rare in infertile men (Hubsmith et al., 1959; Taylor, 1959; Mullaney, 1962; Lyons et al., 1967), but their pathogenesis has not been clearly understood. The spontaneous occurrence of such cysts in animals would be useful. At our institute an inbred strain of rat has been bred and these rats manifest atrophy of the testes and sperm retention cysts in the efferent duct. In rats of this TE strain, all males show these defects. In this communication, we describe the testicular abnormalities and the sperm retention cysts.

\section{Materials and Methods}

Animals. The inbred rat named TE originated in 1974 from an outbred colony of Wistar strain (Wister-Imamichi) rats, that had been maintained in the Institute. A male rat in the colony was detected by palpation as having unilateral atrophy of the testes and was mated with a sibling female. Subsequent inbreedings have been made for 33 generations. The animals are fertile during early adult life and then the testes become atrophic. Animals were therefore mated at about 10 weeks of age and autopsied at about 30 weeks of age to determine the incidence of males with atrophied testes in each generation. Offspring sired by males with atrophic testes were selected for the next generations. Female litter mates have not shown any abnormalities and have received no selection. The incidence of males with an atrophied testis rose gradually with increasing generations and occurred in all males after the 16 th generation.

Animals from the 30th to 33rd generations were used in this investigation. As controls, the IW rat strain, that also originated from the Wistar-Imamichi rat and has been inbred for 30 generations but has not shown testicular abnormality, was used. Animals were maintained in the breeding room at about $24^{\circ} \mathrm{C}$ and were fed a commercial diet (EM; Oriental-kobo Co. Ltd, Tokyo) and tap water ad libitum.

Pathology. The testes of 5 rats were palpated every 5 weeks from 10 to 30 weeks of age to examine changes in testicular size. Animals at 5, 7, 15, 30-36 and 65-80 weeks of age were killed by ether anaesthesia. At each age, 7-15 rats were used. Both testes were removed, weighed separately, and fixed immediately in Bouin's solution. The ipsilateral epididymis, ductus deferens, and genital fat containing the efferent duct were also removed and fixed. After fixation, they were embedded in paraffin wax. The middle portion of the testis was cross-sectioned and the distal portion of the epididymis and the ductus deferens were longitudinally sectioned. Serial sections of the efferent duct and proximal epididymis were made longitudinally. Preparations were stained with haematoxylin and eosin for

\footnotetext{
*Present address: The Imamichi Institute for Animal Reproduction, 1103 Dejima-mura Fukuya, Niihari-gun, Ibaraki-
} ken, 300-01 Japan. 


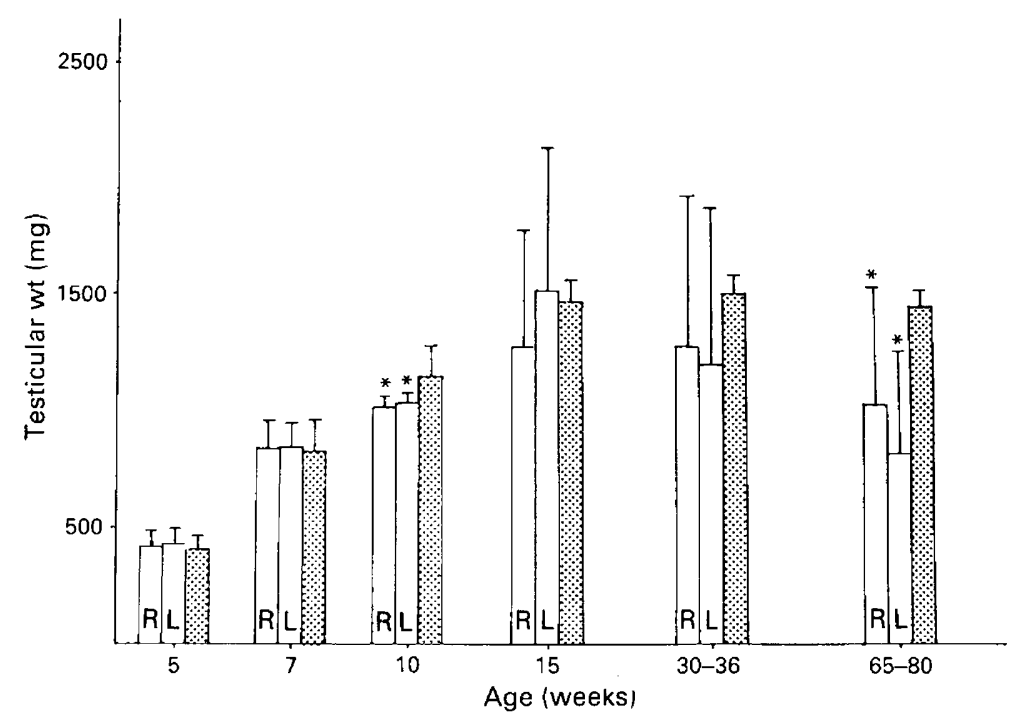

Fig. 1. Testicular weights (mean \pm s.d.) in TE rats (open bars) and in control rats (stippled bar) at various ages. Values of the right testis $(R)$ and of the left testis $(L)$ in TE rats are separately given. ${ }^{*} P<0.05$ compared with control value.

microscopic observations. Three sections of the testis and distal epididymis and 15-20 sections every $100 \mu \mathrm{m}$ of the efferent duct and proximal epididymis were examined. The kidneys, seminal vesicles, prostate gland, and bladder of 5 rats at 30 weeks of age were fixed in neutral buffered formalin and were histologically examined by haematoxylin and eosin staining.

Parabiosis. To elucidate the transferrability of the sperm retention cyst, an adult TE male $(\mathrm{N}=5)$ was united in parabiosis with an IW male $(\mathrm{N}=5)$. Animals were anaesthetized by intraperitoneal injection of pentobarbitone sodium. After clipping and sterilization, the lateral body skin of each animal was cut and then sutured to the other. Recoveries were uneventful. The animals were killed at 25-27 days after the treatment. Longitudinal serial sections of the efferent duct and proximal epididymis were made and transfer of the sperm retention cyst was examined.

Statistical analysis. Values are given as mean \pm s.d. A two-tail $t$ test with unequal variance and Student's $t$ test were used for statistical comparisons. A $P$ value of $<0.05$ was selected as the limit of statistical significance.

\section{Results}

\section{Macroscopic observations}

Abnormality in the TE male was restricted to the testis. No congenital defects in the secondary sex organs such as the epididymis, ductus deferens, seminal vesicle, and prostate gland were observed.

\section{Testicular weight and size}

Testes in the TE rat grew almost normally for 10 weeks. The average weight at 5 and 7 weeks (427.8 and $839.6 \mathrm{mg}$, respectively) did not differ from control values (Fig. 1). The weight at 10 weeks ( $1015.4 \pm 39.6 \mathrm{mg}$ on the right side and $1021.2 \pm 42.1 \mathrm{mg}$ on the left side) was significantly less than the value in the control $(1145.8 \pm 116.8 \mathrm{mg})$, but the difference and variance were small. At 15 weeks the values for the right and left testes did not significantly differ from the control $(1458.4 \pm 97 \cdot 1 \mathrm{mg})$, but the variance was prominent on both sides. In 5 out of 15 rats, atrophied 
Table 1. Testicular defects and sperm retention cysts in TE rats at 15 weeks

\begin{tabular}{|c|c|c|c|c|}
\hline \multirow[b]{2}{*}{ Anim. no. } & \multirow{2}{*}{$\begin{array}{c}\text { Testis } \\
\text { wt (mg) }\end{array}$} & \multirow{2}{*}{$\begin{array}{c}\text { Testis } \\
\text { histology* }\end{array}$} & \multicolumn{2}{|c|}{ Sperm retention cyst } \\
\hline & & & Efferent duct & Epididymis \\
\hline $1 \mathrm{R}$ & 1602 & $\mathbf{N}$ & + & - \\
\hline $\mathrm{L}$ & 2427 & E & + & - \\
\hline $2 \mathrm{R}$ & 881 & A & + & - \\
\hline $\mathrm{L}$ & 1864 & E & + & + \\
\hline $3 \mathbf{R}$ & 883 & A & + & - \\
\hline $\mathrm{L}$ & 2819 & E & + & + \\
\hline $4 \mathrm{R}$ & 1456 & $\mathbf{N}$ & + & - \\
\hline $\mathrm{L}$ & 1456 & $\mathbf{N}$ & + & - \\
\hline $5 \mathrm{R}$ & 1390 & $\mathrm{~N}$ & + & - \\
\hline $\mathrm{L}$ & 1122 & $\mathbf{N}$ & + & - \\
\hline $6 \mathrm{R}$ & 1193 & $\mathbf{N}$ & + & - \\
\hline $\mathrm{L}$ & 1636 & $\mathbf{N}$ & + & - \\
\hline $7 \mathbf{R}$ & 940 & A & + & - \\
\hline $\mathrm{L}$ & 1616 & $\mathbf{N}$ & + & - \\
\hline $8 \mathrm{R}$ & 1117 & $\mathbf{N}$ & + & - \\
\hline $\mathrm{L}$ & 1128 & $\mathbf{N}$ & + & - \\
\hline $9 \mathrm{R}$ & 2059 & E & + & - \\
\hline $\mathrm{L}$ & 867 & A & + & - \\
\hline $10 \mathrm{R}$ & 1120 & $\mathbf{N}$ & + & - \\
\hline $\mathrm{L}$ & 1700 & $\mathrm{E}$ & + & - \\
\hline $11 \mathrm{R}$ & 1888 & E & + & + \\
\hline $\mathrm{L}$ & 1189 & $\mathrm{~N}$ & + & - \\
\hline $12 \mathrm{R}$ & 2270 & E & + & - \\
\hline $\mathrm{L}$ & 996 & A & + & - \\
\hline $13 \mathrm{R}$ & 860 & A & + & - \\
\hline $\mathrm{L}$ & 934 & A & + & - \\
\hline $14 \mathrm{R}$ & 870 & A & + & - \\
\hline $\mathrm{L}$ & 2225 & E & + & - \\
\hline $15 \mathrm{R}$ & 605 & A & + & - \\
\hline $\mathrm{L}$ & 715 & A & + & - \\
\hline
\end{tabular}

*N $=$ normal spermatogenesis; $A=$ most of the seminiferous tubules atrophied; $\mathbf{E}=$ diameter of the seminiferous tubule enlarged.

Table 2. Changes* of individual testicular size

\begin{tabular}{cccccc}
\hline & \multicolumn{5}{c}{ Weeks of age } \\
\cline { 2 - 6 } Anim.no. & 10 & 15 & 20 & 25 & 30 \\
\hline $1 \mathrm{R}$ & - & H & A & A & A \\
L & - & A & A & A & A \\
2 R & - & - & H & H & A \\
L & - & - & H & H & A \\
3 R & - & - & - & - & H \\
L & - & H & A & A & A \\
4 R & - & - & H & H & H \\
L & - & - & - & - & A \\
5 R & - & - & H & H & H \\
L & - & - & H & H & H \\
\hline
\end{tabular}

*_ = normal; $\mathbf{H}=$ hypertrophied; $\mathbf{A}=$ atrophied. 

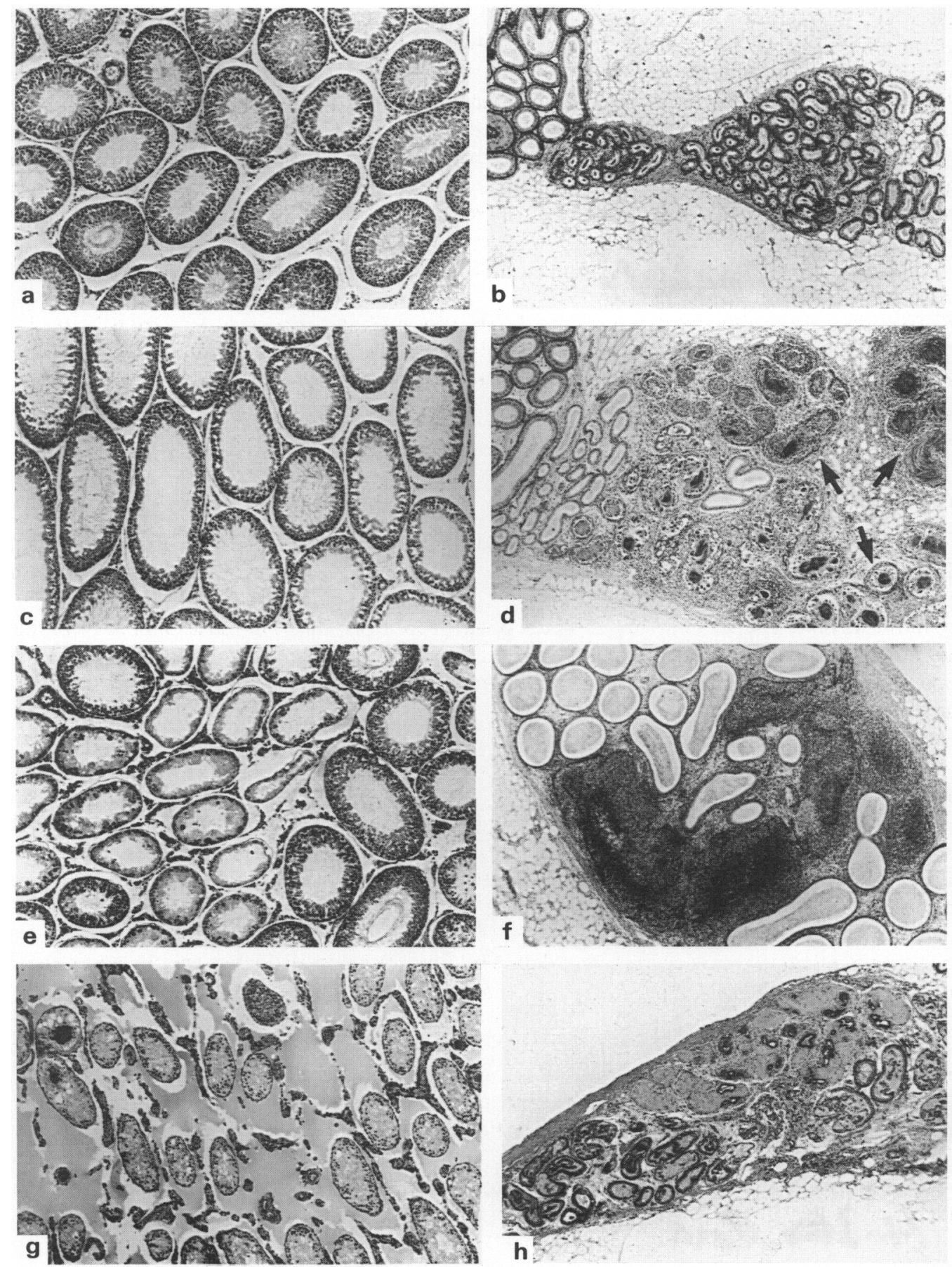

Fig. 2. Testes (a, c, e, g), efferent duct (b, d, h), and epididymis ( $f$ ) of TE rats. At 10 weeks of age, there is normal spermatogenesis (a) and the efferent duct also appears normal (b). At 15 weeks of age, the diameter of the seminiferous tubules has enlarged in the hypertrophied testes (c) and spermatogenesis is arrested in most tubules of the atrophied testis (e), while sperm retention cysts (arrows) are present in the efferent duct of all rats (d) and the epididymis of some rats (f). At 65-80 weeks of age, spermatogenesis is completely arrested (g) and scars are present in the efferent duct (h). a, c, e, g, $\times 40 ; \mathrm{b}, \mathrm{d}, \mathrm{f}, \mathrm{h}, \times 20$. 
testes $(600-1100 \mathrm{mg})$ on one side were seen with enlarged testes $(1700-2800 \mathrm{mg})$ on the contralateral side (Table 1). In 2 rats, both testes were atrophied and there were 2 rats with one testis enlarged and one atrophied. As shown in Table 1, the testes weighing 1100-1700 mg showed no abnormality in histological examination. The term 'atrophy' was therefore used for testes weighing $<1100 \mathrm{mg}$ and 'enlarged' for those $>1700 \mathrm{mg}$ whereas the weight in control rats ranged between 1400 and $1700 \mathrm{mg}$. Testicular growth may stop after 10 weeks in some TE rats. Thereafter, the incidence of rats with atrophied testes gradually increased. At 30-36 weeks of age, the average weight for both sides did not significantly differ from the values in the controls and in the rat at 15 weeks; in 15 rats there were 23 atrophied and 5 enlarged testes. In rats at 65-80 weeks of age, the weight $(1012.7 \pm 509.5 \mathrm{mg}$ on the right side and $804.7 \pm 438.5 \mathrm{mg}$ on the left side) was significantly less than in the controls (1437.4 $\pm 66 \cdot 2 \mathrm{mg}$ ).

To make clear the interrelation between the atrophy and enlargement, testes were palpated in 5 rats from 10 to 30 weeks (Table 2). At 10 weeks, the size was normal. Thereafter, the testes enlarged and then atrophied in most cases. The change in testicular size was so marked that it could be easily detected by palpation.

\section{Histology}

No abnormality appeared in the testis, epididymis, and efferent duct by 10 weeks of age. Normal spermatogenesis was observed in the testis and spermatozoa consistently occurred in the epididymis of rats at 10 weeks (Figs $2 a, b$ ).

In the atrophied testes of rats at 15 weeks of age, about two-thirds of the seminiferous tubules had a decreased diameter and their germinal cell layers were absent. Multi-nucleated giant cells sometimes appeared in the tubules. In the remaining tubules, spermatogenesis was seen (Fig. 2e). In the enlarged testes, seminiferous tubules were uniformly increased in diameter (Fig. 2c). The remaining testes showed no obvious changes.

Sperm retention cysts were observed in every efferent duct of all rats regardless of the incidence of testes with abnormal histology (Table 1). In the duct ipsilateral to the atrophied or enlarged testes, agglutinated spermatozoa occurred throughout in the tubules and the lumen was excessively expanded in places (Fig. 2d). The epithelial cells degenerated and a large number of inflammatory cells mainly composed of lymphocytes and macrophages infiltrated around the agglutinated spermatozoa. In the efferent duct ipsilateral to the testes with normal histology, spermatozoa agglutinated in some part of the tubule and the expansion was less severe. In 3 out of 30 epididymides in 15 rats, large sperm retention cysts occurred with degeneration of the epithelial layer and there was severe infiltration of neutrophils, lymphocytes, and macrophages (Fig. 2f).

In rats at 30-36 weeks of age, histology of the testis and epididymis was similar to that at 15 weeks of age. In the efferent duct, scars were observed in parts of the duct in addition to sperm retention cysts. At $65-80$ weeks of age, the germinal cell layers had degenerated and disappeared almost completely. Calcification was observed in some tubules and oedema was prominently seen in the interstitial area (Fig. $2 \mathrm{~g}$ ). Tubules of the efferent duct disappeared and were replaced by scars (Fig. 2h).

No orchitis was observed in any of the testes examined and no abnormality was seen in the kidney, prostate gland, seminal vesicle, and bladder in 5 rats at 30 weeks.

\section{Parabiosis experiment}

In 3 out of 5 IW rats united by parabiosis with the TE male, sperm retention cysts were observed in the efferent duct (Figs 3a,b). The histology of the cyst was similar to that in the TE male with agglutination of spermatozoa and degeneration of the epithelial cells of the duct. 

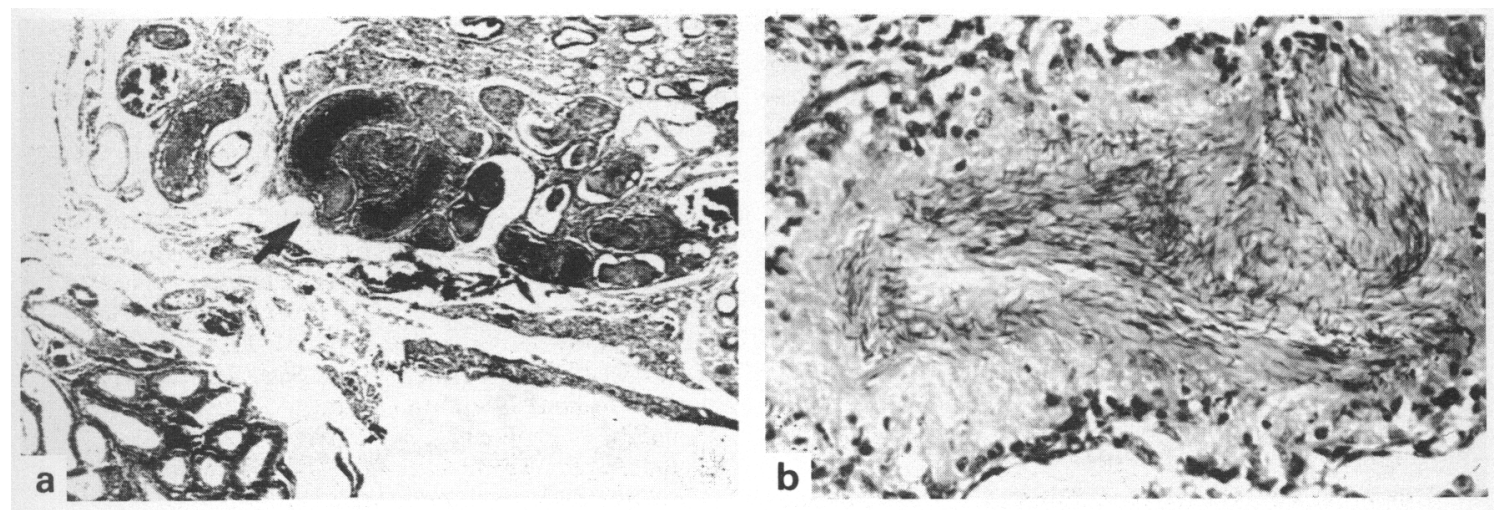

Fig. 3. A sperm retention cyst present in the efferent duct of an IW rat united by parabiosis with a TE rat, showing destruction of the epithelial tissue and infiltration of inflammatory cells mainly composed of lymphocytes and macrophages around agglutinated spermatozoa, $a, \times 20$; b, $\times 200$.

\section{Discussion}

These results show that the TE male is characterized by a sperm retention cyst in the efferent duct and by enlargement and atrophy of testes. The most probable explanation for the pathogenesis of enlargement and atrophy of testes is occlusion of the efferent duct by the cyst. First, the cyst was seen in every efferent duct of all rats at 15 weeks, even when the ipsilateral testicular weight and histology was normal (Table 1) and thereafter testicular abnormality became severe in association with the cyst, indicating that a sperm retention cyst precedes the testicular abnormalities. Second, destruction of epithelial cells in the efferent duct was prominent with expansion of the lumen by agglutinated spermatozoa (Fig. 2d). Third, it is apparent from periodic palpation of individual testes that the enlargement precedes the atrophy in most cases (Table 2). This finding indirectly supports that obstruction of the efferent duct occurred in the TE males, since similar changes in testicular weight and histology have been reported for rats in which the ducts have been ligated. In such rats, ligation produced a rapid increase in testicular weight and enlargement in diameter of seminiferous tubules because of accumulation of fluid and then the testes became atrophic (Neaves, 1973; Anton, 1979).

Pathogenesis of sperm retention cysts has been attributed to direct or surgical trauma (Hubsmith et al., 1959; Mullaney, 1962; Lyons et al., 1967), lower urinary tract infection (King, 1955), chemical agents (Cooper \& Jackson, 1973; Bhathal et al., 1974), congenital failure of the efferent duct to connect with the epididymal tubule (King, 1978), and autoimmune disorders after vasectomy (Schmidt, 1966). In the TE male, trauma, infection, and chemical agents can be excluded. Failure of connection, as occurs in TW rats of similar origin (Ajisawa et al., 1985; Ikadai et al., 1985) can also be excluded since spermatozoa were observed in the epididymis of rats at 10 weeks of age. Pathogenesis may therefore be due to an autoimmune disorder. The occurrence of cysts in a normal male united by parabiosis to a TE male indicates that transmissible factors may be involved in this defect. Rats of the TE line will be of value for the study of pathogenesis of sperm retention cysts in man and animals.

We thank Dr S. Imai for advice on the statistical analysis and Dr M. Yoshida for valuable suggestions for the pathological examinations. 


\section{References}

Ajisawa, C., Ikadai, H. \& Imamichi, T. (1985) Morphological study on the hypoplastic testis with aplasia of the epididymis, ductus deferens, and gland of ductus deferens in the TW inbred rat. Exp. Anim. 34, 189-195.

Anton, E. (1979) Early ultrastructural changes in the rat testis after ductuli efferentes ligation. Fert. Steril. 31, 187-194.

Bhathal, P.S., Gerkins, J.F. \& Mashford, M.L. (1974) Spermatic granuloma of the epididymis in rats treated with guanethidine. J. Path. 112, 19-26.

Cooper, E.R.A. \& Jackson, H. (1973) Chemically induced sperm retention cysts in the rat. J. Reprod. Fert. 22, 213-222.

Hubsmith, R.J., Garret, R. \& Photos, C. (1959) Granulomatous orchitis and epididymis. J. Urol. 81, 301-304.

Ikadai, H., Sakuma, Y., Suzuki, K. \& Imamichi, T. (1985) Congenital abnormalities of the male genital organs in the newly established TW rat strain. Cong. Anom. $25,65-7 \mathrm{l}$.

King, E.S.J. (1955) Spermatozoal invasion of the epididymis. J. Path. Bact. 70, 450-467.
King, N.W. (1978) Testis and epididymis. In Pathology of Laboratory Animals, pp. 554-580. Eds K. Bernirschke, F. M. Garner \& T. C. Jones. Springer-Verlag, New York.

Lyons, R.C., Petre, J.H. \& Lee, C.N. (1967) Spermatic granuloma of the epididymis. J. Urol. 97, 320-323.

Mullaney, J. (1962) Granulomatous lesions associated with spermatozoal invasion of the interstitial tissue of the epididymis. Br. J. Urol. 34, 351-355.

Neaves, W.B. (1973) Permeability of Sertoli cell tight junctions to lanthanum after ligation of ductus deferens and ductuli efferentes. J. Cell Biol. 59, 559-572.

Schmidt, S.S. (1966) Technics and complications of elective vasectomy. Fert. Steril. 17, 467-482.

Taylor, J.B. (1959) Spermatic granuloma. Br. J. Urol. 31, 169-200.

Received 2 June 1987 